\title{
Palmoplantar Pustulosis: Recent Advances in Etiopathogenesis and Emerging Treatments
}

\author{
Magdalena Misiak-Galazka ${ }^{1}$ Joanna Zozula ${ }^{1}$ - Lidia Rudnicka' ${ }^{10}$
}

Published online: 1 February 2020

(c) The Author(s) 2020

\begin{abstract}
Palmoplantar pustulosis (PPP) is a chronic, recurrent skin disease belonging to the spectrum of psoriasis. It is characterized by an eruption of sterile pustules on the palms and soles. Recent studies in PPP have focused on genetic differences between pustular phenotypes and the role of the innate immunological system and the microbiome in the etiopathogenesis of the disease. Mutations in IL36RN (a major predisposing factor for generalized pustular psoriasis) were found in selected patients with PPP and were associated with earlier disease onset. Studies have shown that the interleukin (IL)-17 and IL-36 pathways might be involved in the pathogenesis of PPP. A microbiome has been demonstrated in the vesicopustules of PPP, and an abundance of Staphylococcus appears to be increased by smoking. Improved understanding of the underlying etiopathogenesis of PPP has led to advances in treatment options, and targeted therapies for PPP have been evaluated or are under evaluation against more than 12 molecules in ongoing clinical trials. These targets include CXCR2 (IL-8 receptor type B), granulocyte colony-stimulating factor receptor, IL-1 receptor, IL-8, IL-12, IL-23, IL-17A, IL-17 receptor, IL-36 receptor, phosphodiesterase- 4 , and tumor necrosis factor- $\alpha$.
\end{abstract}

\section{Key Points}

The genetic background of palmoplantar pustulosis (PPP) is complex and differs from that of other types of psoriasis.

Recent studies have focused on the role of the interleukin (IL)-17 pathway, the IL-36 pathway (with overexpression of IL-8), and the microbiome in the etiopathogenesis of PPP.

Ongoing clinical trials in PPP are devoted to an IL-1 inhibitor (anakinra), an IL-8 receptor type B inhibitor (RIST4721/AZD4721), an IL-17 receptor A inhibitor (brodalumab), IL-36 inhibitors (ANB019 and BI 655,130 [spesolimab]), and an inhibitor of the granulocyte colony-stimulating factor receptor (CSL324).

Lidia Rudnicka

lidiarudnicka@gmail.com

1 Department of Dermatology, Medical University of Warsaw, Koszykowa 82A, 02-008 Warsaw, Poland

\section{Introduction}

Palmoplantar pustulosis (PPP) or palmoplantar pustular psoriasis (PPPP) affects the palms and/or the soles and is characterized by eruptions of sterile pustules on an erythematosquamous background. The prevalence of PPP is estimated to range from 0.01 to $0.05 \%$ [1]. A nationwide study in a Japanese population found a PPP prevalence of $0.12 \%$ [2]. PPP is more common among females, with a prevalence ranging from $65.3 \%$ in a Japanese study [2] to $94 \%$ in a Swedish study [3]. The mean age of patients ranges from 40 to 58 years [4-7]. Whether PPP and PPPP are two entities or different presentations of the same disease remains under discussion in the literature. In many publications, if lesions are limited to the palms/soles, the term "palmoplantar pustulosis" is used, whereas PPPP presents with concomitant plaque psoriasis lesions in other parts of the body or/and with a positive family history for psoriasis. In a European consensus on the phenotypes of pustular psoriasis published in 2017, the term "palmoplantar pustulosis" was used. PPP was described as primary, persistent ( $>3$ months), sterile, macroscopically visible pustules on the palms and/or soles, then subclassified as with or without psoriasis vulgaris.

The aim of this review is to present current data on PPP, focusing mainly on recent advances in etiopathogenesis and 
emerging treatments. We searched the Embase, MEDLINE (accessed via PubMed), and Cochrane Central Register of Controlled Trials databases and http://clinicaltrials.gov using the terms "pustulosis palmoplantaris" OR "palmoplantar pustulosis" OR "palmoplantar pustular psoriasis". In total, 332 full-text articles were screened, of which 129 were included in this publication, focusing on the essential and most recent data.

\section{Clinical Presentation}

The primary lesion in PPP is a pustule on an erythematous and desquamative background. Lesions are localized on the palms and/or soles with a chronic and relapsing course $[6,7]$. Patients may present with other lesions on different parts of the body as well as nail changes. The most common concomitant lesions are psoriasis vulgaris type, which were present in $24-84.21 \%$ of cases [5-9]. Nail changes were observed in 30-76\% of cases [5, 7-11]. Recently, Hiraiwa and Yamamoto [11] published a retrospective review of nail changes in PPP. The most common finding was onycholysis $(14 / 28$ [50\%]), followed by pitting (42.9\%) and destruction of the nail (39.3\%). Other nail changes included scale, subungual hyperkeratosis, subungual pustulation, indention, transverse and longitudinal ridging, curvature abnormalities, discoloration, splinter hemorrhage, and thickening of the nail [11].

\section{Triggering Factors}

\subsection{Smoking}

Smoking is the best-known triggering factor in PPP. In different studies, $42-100 \%$ of patients with PPP were active smokers or reported smoking in the past $[3,5,7,12]$.

\subsection{Infections and Stress}

Infections and stress, well-known triggering factors in psoriasis vulgaris, may exacerbate PPP. Tonsillitis $[13,14]$ and dental infections $[15,16]$ were the most commonly reported infections. Control of dental infection leads to clinical improvement in more than half of patients with PPP [15].

\subsection{Metal Allergy}

Dental metal allergy is a potential triggering factor for PPP [15-19]. In several Japanese studies, positive metal patch tests were observed in 50-69.8\% of patients. The most common metal allergens were nickel, mercury, gold, palladium, chromium, and platinum $[15,16,20]$. However, recent studies have indicated that, despite positive metal patch test results, removal of dental metal led to improvement in only a select group of patients. Dental infection should be controlled before removal of any dental metal $[15,16]$. Brunasso Vernetti et al. [21] recently published a systematic review on contact allergy in PPP. Positive patch tests were found in $23.3 \%$ of cases (121/519), with metals being the most common allergens. In $58.3 \%$ of cases (28/48), withdrawal of allergens led to improvement of skin lesions. These results support the need for patch testing in patients with PPP [21].

\subsection{Triggering Drugs}

Among drugs that might induce or exacerbate palmoplantar pustular lesions, the most common are anti-tumor necrosis factor (TNF) agents. Bae et al. [22] reported an increased risk of developing PPP among patients with inflammatory bowel disease treated with anti-TNF agents, especially in male and younger patients (aged 10-39 years): hazard ratio (HR) 19,682 (95\% confidence interval [CI] 3867-100169) and HR 14.318 (95\% CI 2.915-70.315), respectively.

\section{Concomitant Diseases}

\subsection{Thyroid Disease}

The association between PPP and thyroid dysfunction is well-known and has been confirmed in many studies, with an average prevalence of $20-40 \%$ [5-7, 12, 23, 24].

\subsection{Metabolic Syndrome}

Metabolic syndrome defines risk factors that lead to an increased risk of type 2 diabetes mellitus (T2DM) and cardiovascular disease. Misiak-Galazka et al. [7] reported metabolic syndrome in $30 \%$ of PPP cases compared with $32 \%$ of patients with psoriasis vulgaris $(p=0.81)$, whereas Trattner et al. [25] found metabolic syndrome in $26 \%$ of patients with PPP.

Obesity (body mass index $[\mathrm{BMI}]>25 \mathrm{mg} / \mathrm{m}^{2}$ ) was observed in $18-62 \%$ of patients with PPP, and BMI $>30 \mathrm{mg} /$ $\mathrm{m}^{2}$ was observed in $22 \%$ of cases [7, 9, 25]. Wilsmann-Theis et al. [9] showed that the highest BMI was in patients with PPP onset at age $<40$ years and the lowest in patients with PPP onset $>65$ years. These results suggested that obesity might be an important factor in PPP, especially in younger patients.

In many studies, T2DM was observed in $7.7-19 \%$ of patients [2, 7, 9, 25]. However, Ataş and Gönül [24] showed no significant difference between the fasting glucose, insulin, and homeostatic model assessment between a group with PPP and controls. The incidence of hyperlipidemia in 
patients with PPP ranges from 10.2-49\% in different populations $[2,5,25,26]$ and is a risk factor for ischemic heart disease and hypertension. Several studies have reported ischemic heart disease and hypertension to be present in $12.7-24.6 \%[7,26]$ and $28.5-38.3 \%[9,25,26]$ of patients with PPP, respectively.

\subsection{Atopy}

Several studies have reported allergic diseases such as atopic dermatitis, asthma, and rhinitis allergica (range 2-17\%), but the association between PPP and atopy remains unknown $[7,9]$.

\subsection{Arthritis}

Joint pain often accompanies palmoplantar pustular lesions. In most cases, psoriatic arthritis is diagnosed, followed by synovitis-acne-pustulosis-hyperostosis-osteomyelitis syndrome (SAPHO). The prevalence of psoriatic arthritis ranges from 10 to $25.6 \%$ of PPP cases [5, 9, 25]. SAPHO syndrome belongs to the group of spondyloarthropathies and is characterized by the presence of osteo-articular manifestations with or without skin lesions. According to Benhamou et al. [27], typical osteo-articular manifestations of PPP include inflammatory synovitis, pseudoseptic arthritis, hyperostosis, osteitis, spondylitis, or spondylodiscitis. Pustulotic arthroosteitis (PAO), a term commonly used in the literature, can be classified as a subtype of SAPHO [27].

\subsection{Coeliac Disease}

Swedish studies have shown a high prevalence of antigliadin and anti-tissue transglutaminase antibodies, coeliac disease, and disturbed calcium homeostasis in patients with PPP [3, $6,28]$. However, a study in German and Polish populations did not confirm these observations, and these laboratory tests are not routinely performed in patients with PPP in our clinical practice $[7,29,30]$.

\section{Quality of Life and Psychiatric Disorders}

Palmoplantar pustular lesions are often accompanied by pain and pruritus, leading to decreased health-related quality of life (HRQoL). Palmoplantar subtypes of psoriasis, both pustular and nonpustular, are associated with more impaired quality of life than are other types of psoriasis using different HRQoL tools [31-34]. The most commonly used and easiest tool with which to evaluate quality of life in dermatological conditions is the Dermatology Life Quality Index (DLQI), which consists of ten questions. Trattner et al. [25] showed that the mean DLQI score was $7 \pm 6$ among 102 patients with
PPP; $24.7 \%$ of patients had moderate and $27.3 \%$ had severe or very severe impairment of their quality of life, confirming earlier observations [25, 31-34]. Moreover, Wilsmann-Theis et al. [9] showed a significant positive correlation between Palmoplantar Pustulosis Area and Severity Index (PPPASI) and DLQI scores $(r=0.45, p<0.05)$.

Depression is the most common of the psychiatric disorders in patients with PPP, with prevalence ranging between 13 and $28.8 \%$ [7, 25, 26, 28]. Other psychiatric conditions that accompany PPP are bipolar disorder, schizophrenia, anxiety, and eating disorders [26, 28].

\section{Genetic Studies}

Many genetic studies have shown various mutations in IL36RN, ASP1S3, CARD14 genes among different pustular psoriasis subtypes and different ethnicities. IL36RN encodes the IL-36 receptor antagonist (IL-36Ra), which blocks the activation of IL-36 receptor signaling. IL-36 signaling is known to have a role in innate and adaptive immune responses [35]. AP1S3 encodes a subunit of the adaptor protein 1 complex. It has been shown that the adaptor protein complexes are responsible for endosomal transport within the cells, including translocation of toll-like receptor 3 [36]. CARD14 encodes a keratinocyte nuclear factor $\mathrm{\kappa B}$ adaptor protein CARD14, which plays a role in the innate immune response. Different CARD14 variants are associated with diverse inflammatory diseases [37].

\subsection{IL36RN Mutations}

The first studies found a mutation in IL36RN in patients with generalized pustular psoriasis, and mutations in IL36RN are regarded as a major predisposing factor for generalized pustular psoriasis (GPP) [38-40]. However, IL36RN mutations have been found in only a small proportion of patients with PPP, and no association between IL36RN mutation and PPP has been found [41-43].

More recently, Twelves et al. [44] characterized the clinical and genetic features of different forms of pustular psoriasis in 863 patients primarily from Europe, Asia, and Africa. Mutations in IL36RN were found in 12 of 234 (5.1\%) patients with PPP and were less frequent than in GPP and acrodermatitis continua of Hallopeau (ACH) (23.7 and $18.2 \%$, respectively). However, the association between PPP and IL36RN mutations is statistically significant. Mutations in IL36RN are associated with an early onset of disease in all types of pustular psoriasis. Twelves et al. [44] suggested that patients with PPP aged $<40$ years should be screened for IL36RN mutations. 


\subsection{CARD14 and AP1S3 Mutations}

Recent studies have reported CARD14 mutations in several patients with PPP, especially male patients and those with a negative family history of psoriasis vulgaris [44-46]. Recent studies also showed AP1S3 mutations in selected patients with PPP and in patients with GPP $[41,44]$.

\subsection{PSORS1}

PSORS1 is the most potent known genetic risk factor for psoriasis vulgaris [47]. Asumalahti et al. [47] and Mossner et al. [45] found no association between PPP and the alleles of PSORS1 (HLA-Cw*6, HCR*WWCC, $\mathrm{CDSN}^{*}$ 5).

\subsection{Tumor Necrosis Factor (TNF)-238 and -308 Promoter Polymorphisms}

Genetic analyses of TNF-238 and -308 promoter polymorphisms in PPP, psoriasis vulgaris, and psoriatic arthritis showed no association between polymorphisms and PPP compared with psoriasis vulgaris and psoriatic arthritis [48].

Moreover, the association between TNF $\alpha$-induced protein 3 interacting protein $1(T N I P 1)$ gene and psoriasis vulgaris have been confirmed. However, no association between six TNIPl gene polymorphisms and PPP in the Chinese Han population was found [49].

In conclusion, the above-mentioned studies have shown the genetic distinctness of PPP compared with psoriasis vulgaris (PSORS1, TNF-238, and -308 promoter polymorphisms, TNIPI gene polymorphisms) and generalized pustular psoriasis (IL36RN mutation). The mutations in other genes were found only in selected patients with PPP. The significance of mutations in many genes in PPP appears complex and requires further study.

\section{Histology}

The main characteristic histologic feature of PPP is intraepidermal unilocular pustules filled with neutrophils and eosinophils. However, PPP can be classified into the vesicle, pustulovesicle, and pustule phases, and pustules are not seen in every case. The principal differential diagnosis, both clinically and histopathologically, is pompholyx, which has two phases: vesicle and pustule [50]. A few studies have been published on histopathological differences between PPP and pompholyx [50-53]. It has also been suggested that the acrosyringium (i.e., intraepidermal duct of the eccrine glands) is the primary site of vesicle/pustule formation in PPP, in comparison with pompholyx, where the acrosyringium is damaged and rupture is secondary to inflammation [51].
Masuda-Kuroki et al. [50] recently described a new fourpoint checklist to distinguish PPP from pompholyx. Histopathological features favoring PPP are "vesicles lacking spongiosis" and "microabscesses on the edges of vesicles". On the other hand, histopathological features favoring pompholyx are "vesicles with spongiosis" and "neutrophils only on the top, and no microabscesses on the edges of vesicles" [50].

\section{Etiopathogenesis}

\subsection{Acrosyringia}

Several histologic and pathophysiologic studies have reported that the inflammatory process in PPP lesions starts in the acrosyringia, leading to their destruction $[6,51,54]$. Other studies have shown that the cholinergic system is involved in the inflammatory process, with changes in the expression of nicotinic acetylcholine receptors and enzymes: choline acetyltransferase and acetylcholinesterase in the skin of patients with PPP [55, 56]. An association has been reported between nicotine and the cholinergic system that seems to be based on excretion of nicotine in the eccrine ducts. Nicotine probably changes the expression of antigens in the acrosyringium, attracting Langerhans cells, and may induce production of IL-17 in the palms and soles [57].

\subsection{Tonsillitis}

Another pathophysiological concept is based on the fact that infection, including acute tonsillitis, might exacerbate PPP. The association between the tonsils and PPP was studied because tonsillectomy might be beneficial in this group of patients with PPP [13,14]. Several studies have shown that a hyperimmune response to $\alpha$-streptococci activates tonsillar $\mathrm{T}$ cells, which express several receptors, including cutaneous lymphocyte-associated antigen (CLA), chemokine receptor 6 , and $\beta-1$ integrin [14, 58-60]. Nozawa et al. [14] showed that the number of tonsillar lymphocytes expressing CLA was increased in tonsillar mononuclear cells and tonsillar tissues in patients with PPP compared with in healthy controls. Activated tonsillar T cells migrate to PPP skin, causing inflammation [14].

\subsection{Interleukin (IL)-17 Pathway}

Other studies have shown that IL-17A is increased in PPP. IL-17 plays a role in the activation and infiltration of neutrophils and takes part in the primary immunological response, stimulating the production of many cytokines [57, 61, 62]. Bissonnette et al. [61] showed a significant increase in the expression of IL-1 $\beta$, IL-6, LL-37, IL-19, 
IL-17A, CXCL1, and CXCL2 in PPPP skin compared with nonpustular palmoplantar psoriasis, but found no significant difference in the expression of IL-23 in PPPP as compared with psoriasis [62]. The results suggested that IL-17 might play a crucial role in inflammation in PPP but that IL-23 may not be as crucial in PPP development as in psoriasis vulgaris. IL-17 is produced by not only T-helper type 17 (Th17) cells but also by neutrophils and mast cells [63]. Lesiak et al. [29] found elevated levels of IL-15 and IL-22 in the sera of female patients with PPP. We know that IL-15 induces IL-17 production and IL-22 enhances the proinflammatory action of IL-17 [29].

\subsection{IL-36 Pathway}

IL-8 is regarded as a potent chemoattractant and activator of neutrophils and a major factor inducing pustule formation [64]. IL-8 messenger RNA (mRNA) was shown to be upregulated in the lesional skin of patients with PPP and the expression to be upregulated by LL-37, the mature form of cathelicidin [65, 66]. Xiaoling et al. [67] evaluated

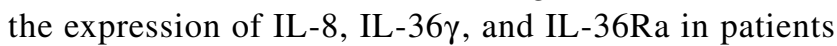
with PPP. IL-36 $\gamma$ belongs to the IL-1 family and stimulates keratinocytes to produce IL-8. IL-36Ra, encoded

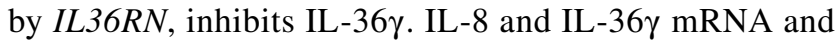
protein were shown to be significantly increased in PPP lesional skin compared with in healthy controls. IL-36Ra mRNA was markedly overexpressed in PPP lesions compared with healthy skin, but IL-36Ra protein expression did not differ between PPP, psoriasis vulgaris, and healthy skin. IL-8 and IL-36y were also shown to be related to acrosyringia in pustule formation [67].

Blockage of the IL-36 pathway is a new treatment concept in PPP, and studies of the use of monoclonal antibodies against the IL-36 receptor are ongoing. Moreover, an ongoing phase IIa study is investigating the role of RIST4721/AZD4721, which blocks CXCR2, in PPP. CXCR2 (IL-8 receptor type B) mediates the action of IL-8 [68].

\subsection{Lipocalin 2}

Wolk et al. [69] found an increased level of lipocalin 2 in serum samples of patients with PPP. The increase was primarily upregulated by IL- $1 \beta$. These authors also reported a significant positive relationship between lipocalin 2 levels and pustule score.

In conclusion, the above-mentioned studies indicate that the innate immunological response may play a crucial role in the pathophysiology of PPP and be more critical than in psoriasis vulgaris [61].

\subsection{Microbiome}

Studies devoted to the microbiome in patients with PPP have been recently published. Masuda-Kuroki et al. [70] showed that a microbiome exists in the vesicopustules of patients with PPP. Bacteria were found in 13 of 43 (30.2\%) pustulovesicles (from 26 patients with PPP). In the phylumlevel analysis, the most abundant bacteria were Firmicutes, Proteobacteria, Actinobacteria, and Bacteroidetes. In a genus-level analysis, Staphylococcus, Devosia, and Pseudonocardia were the most relatively abundant bacteria in pustulovesicles. Interestingly, a significant difference was seen in the abundance of Staphylococcus between smoking and nonsmoking patients with PPP, with more bacteria found in patients who smoked [70]. Kouno et al. [71] surveyed the microbiota of saliva collected from 12 patients with PPP (seven of whom had concomitant PAO) and ten healthy controls. They observed that patients with PAO had less Proteobacteria at the phyla level and less Hemophilus and more Prevotella at the genus level than healthy controls $(p<0.05)$. Moreover, smoking patients had more Firmicutes. This preliminary study showed oral dysbiosis in Japanese patients with PPP, particularly with concomitant PAO [71].

The results of these studies conflict with the disease definition of a "sterile" pustule. The method of bacteria detection in these recent studies involved amplification and sequencing of bacterial ribosomal RNA genes rather than using culturing methods. This approach has the advantage of being able to identify dead bacteria as well as those that cannot be cultivated in laboratory conditions [70, 71].

\section{Treatment}

The treatment of PPP involves both topical and systemic modalities, as well as phototherapy and targeted therapies.

\subsection{Topical Treatment}

In everyday practice, topically potent glucocorticosteroids, vitamin D derivatives, retinoids, keratolytic agents, and emollients are used, based mostly on long clinical experience. Several studies of topical treatments in PPP have been published. Two studies showed the efficacy of topical maxacalcitol (22-oxacacitriol, vitamin $\mathrm{D}_{3}$ analog) [72, 73]. Umezawa et al. [73] conducted a clinical trial and stated that 87 of $94(92.55 \%)$ patients reported improvement (marked, moderate, or mild) in skin lesions after treatment with maxacalcitol twice daily for 8 weeks, compared with 70 of $93(75.25 \%)$ of those receiving placebo; $p<0.0001$. Muro et al. [72] found that combination therapy with 
maxacalcitol ointment and betamethasone butyrate propionate ointment was more effective than monotherapy with betamethasone butyrate propionate. A case report described improvement of PPP with crisaborole (a topical phosphodiesterase-4 [PDE-4] inhibitor) [74], and a case report of the use of tacrolimus $1 \%$ ointment twice daily has also been published [75].

New topical treatments for PPP are needed, as many patients have concomitant diseases and contraindications to systemic treatment.

\subsection{Phototherapy}

Psoralen plus ultraviolet A (PUVA) therapy, narrow band ultraviolet B (NB-UVB) phototherapy, excimer light therapy, and photodynamic therapy (PDT) are all used in the treatment of PPP. They are well-tolerated, with the most common side effects being transient superficial skin erythema, burn, and pain. Most studies describe PUVA therapy. PUVA has shown moderate efficacy [76], and Riad et al. [77] reported good responses in $46.7 \%$ of patients. However, Jensen et al. [78] used PUVA soak in 21 patients with PPP and reported rapid relapses and no positive value from the treatment. The efficacy of PUVA increases in combination with oral retinoids, mainly acitretin $[79,80]$.

NB-UVB phototherapy with a flat-type fluorescent lamp resulted in moderate to marked improvement in $73.3 \%$ of 16 patients with PPP and a $61.4 \%$ reduction in a modified PPPASI [81]. However, both paint PUVA and UVA-1 appear to be superior to UVB therapy [82, 83].

In a pilot randomized controlled study, $68.8 \%$ of patients showed marked improvement with UVA-1 phototherapy and only $34.4 \%$ during NB-UVB treatment [82]. Another study confirmed the efficacy of UVA-1: PPPASI-50 was observed in $48.4 \%$ of patients with PPP after 15 sessions and in $90.3 \%$ of patients after 30 sessions of high-dose UVA-1 $\left(80 \mathrm{~J} / \mathrm{cm}^{2}\right)$ phototherapy [84].

Another treatment option for patients with PPP is monochromatic excimer light, which has shown efficacy in $44.1-75 \%$ of cases [85-89].

PDT appears to have limited efficacy in PPP [90]. A guideline for topical PDT published by the British Photodermatology Group and the British Association of Dermatologists did not recommend 5-aminolevulinic acid-PDT as an effective therapy for psoriasis [91].

Furthermore, in a study in nine patients with PPP, three courses of Grenz ray therapy at a dose of 5 Gy per treatment produced marked improvement, and the improvement was sustained for 3 months' follow-up [92].

In conclusion, phototherapy is regarded as a well-established treatment with a good response rate, but frequent relapses are observed.

\subsection{Systemic Treatment}

Acitretin is the most commonly used systemic treatment in PPP, and many authors regard it as a primary systemic treatment. A systemic literature review by Sevrain et al. [93] suggested acitretin as a second-line treatment in PPP without psoriatic arthritis. Data are conflicting regarding the use of alitretinoin in PPP. Irla et al. [94] showed that PPPASI-50 was achieved by $100 \%$ of patients, and PPPASI- 75 was achieved by $57 \%$ of patients at week 12 , but Reich et al. [95] found no significant differences between alitretinoin $30 \mathrm{mg}$ and placebo in the treatment of PPP and concluded there was no evidence to support further studies. Nonetheless, Brunasso et al. [96] stated that more extensive studies are needed to evaluate the efficacy of alitretinoin in PPP.

According to a Cochrane systematic review on treatments for chronic PPP, data confirm the use of acitretin and oral PUVA or combination therapy, i.e., retinoid PUVA. Lowdose cyclosporin, tetracycline, and Grenz ray therapy may be beneficial for patients with PPP [97]. Methotrexate had lower efficacy in PPP and is regarded as a second-line treatment mainly in patients with concomitant psoriatic arthritis [93].

\subsection{Targeted Therapies Approved for Psoriasis Vulgaris}

In the last 20 years, many targeted agents have been approved for the treatment of psoriasis vulgaris, and many studies have evaluated these agents in PPP (Table 1). Moreover, eight studies are investigating emerging agents that are yet to be approved in PPP (see Table 2 and Sect. 9.5).

\subsubsection{IL-12/23 Inhibitors}

9.4.1.1 Ustekinumab (Anti-IL-12/23) The largest body of evidence is that for the use of ustekinumab in PPP, but data on the efficacy can be conflicting [62,98-101]. A prospective, randomized, placebo-controlled study by Bissonnette et al. [62] showed no statistically significant difference in efficacy between ustekinumab $45 \mathrm{mg}$ and placebo in patients with PPPP or PPP. Bertelsen et al. [102] and Gerdes et al. [103] reported ustekinumab to have limited efficacy. Morales-Múnera et al. [99] reported a positive response to ustekinumab. In another study, Au et al. [98] found greater efficacy with subcutaneous ustekinumab $90 \mathrm{mg}$ than with $45 \mathrm{mg}$. Six of nine $(67 \%)$ subjects receiving ustekinumab $90 \mathrm{mg}$ achieved clinical clearance compared with only one of eleven (9\%) subjects receiving the $45-\mathrm{mg}$ dose $(p=0.02)$ [98].

9.4.1.2 Guselkumab (Anti-IL-23) Studies on the use of guselkumab in PPP have been published. Terui et al. [104] 


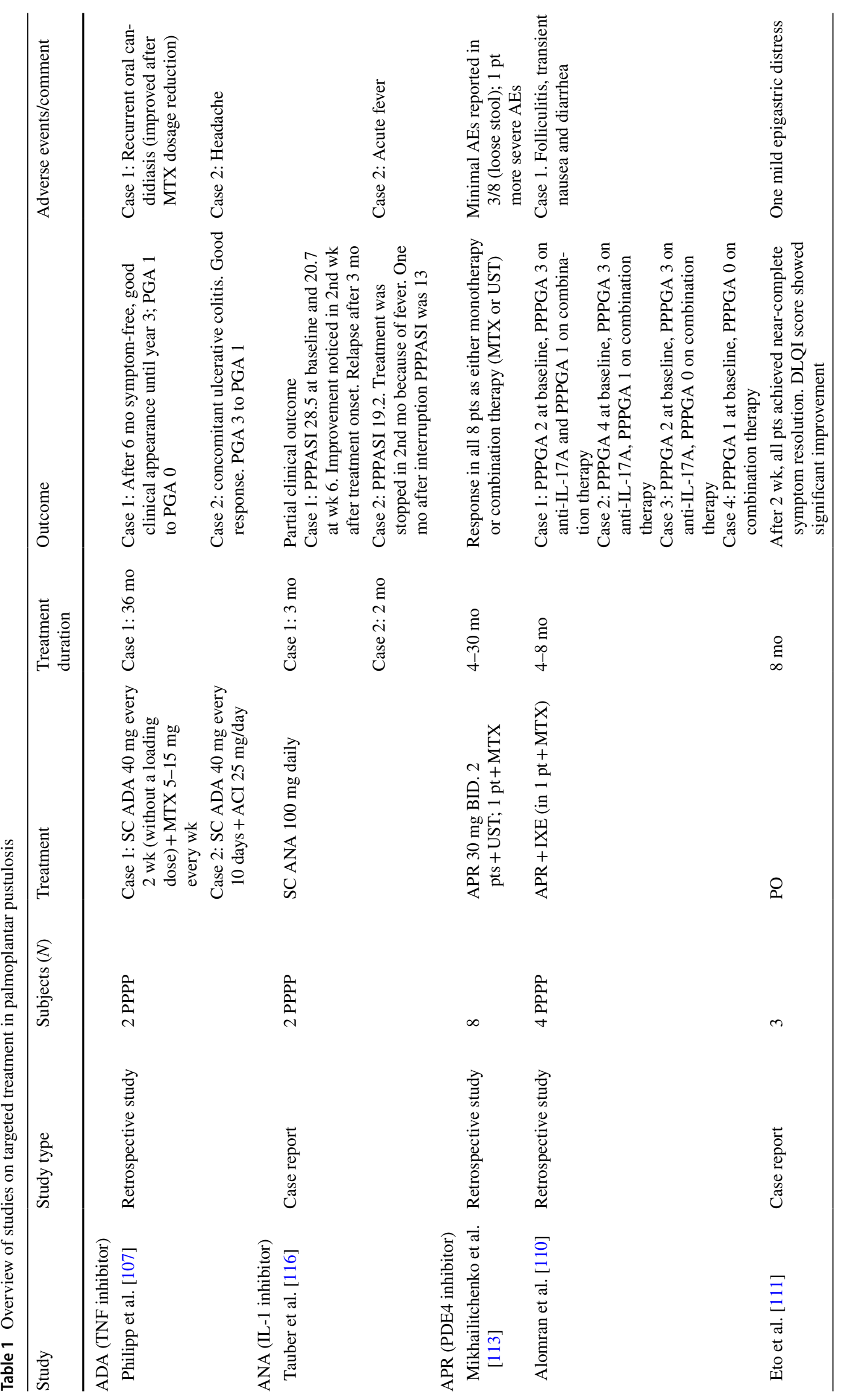




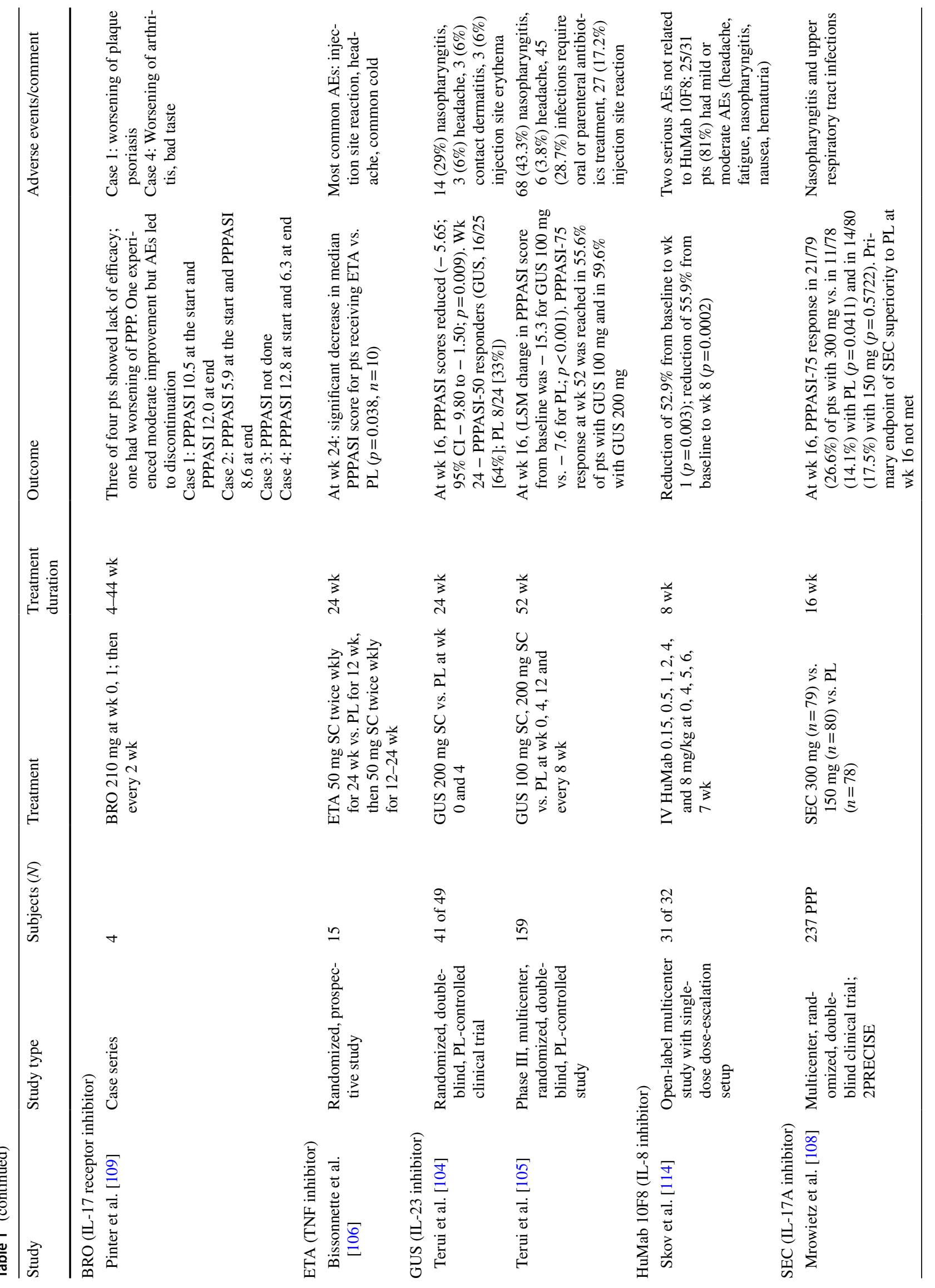




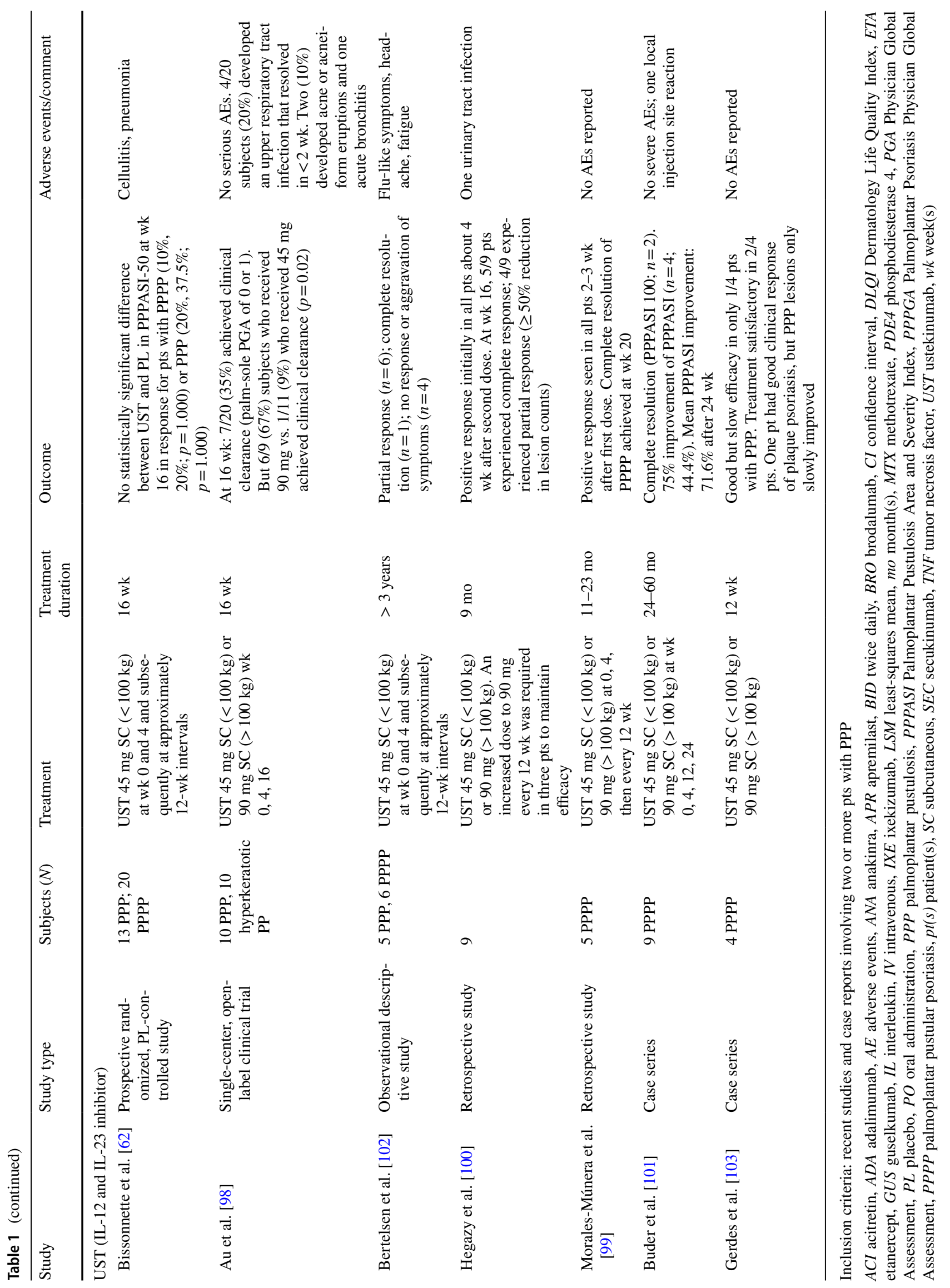




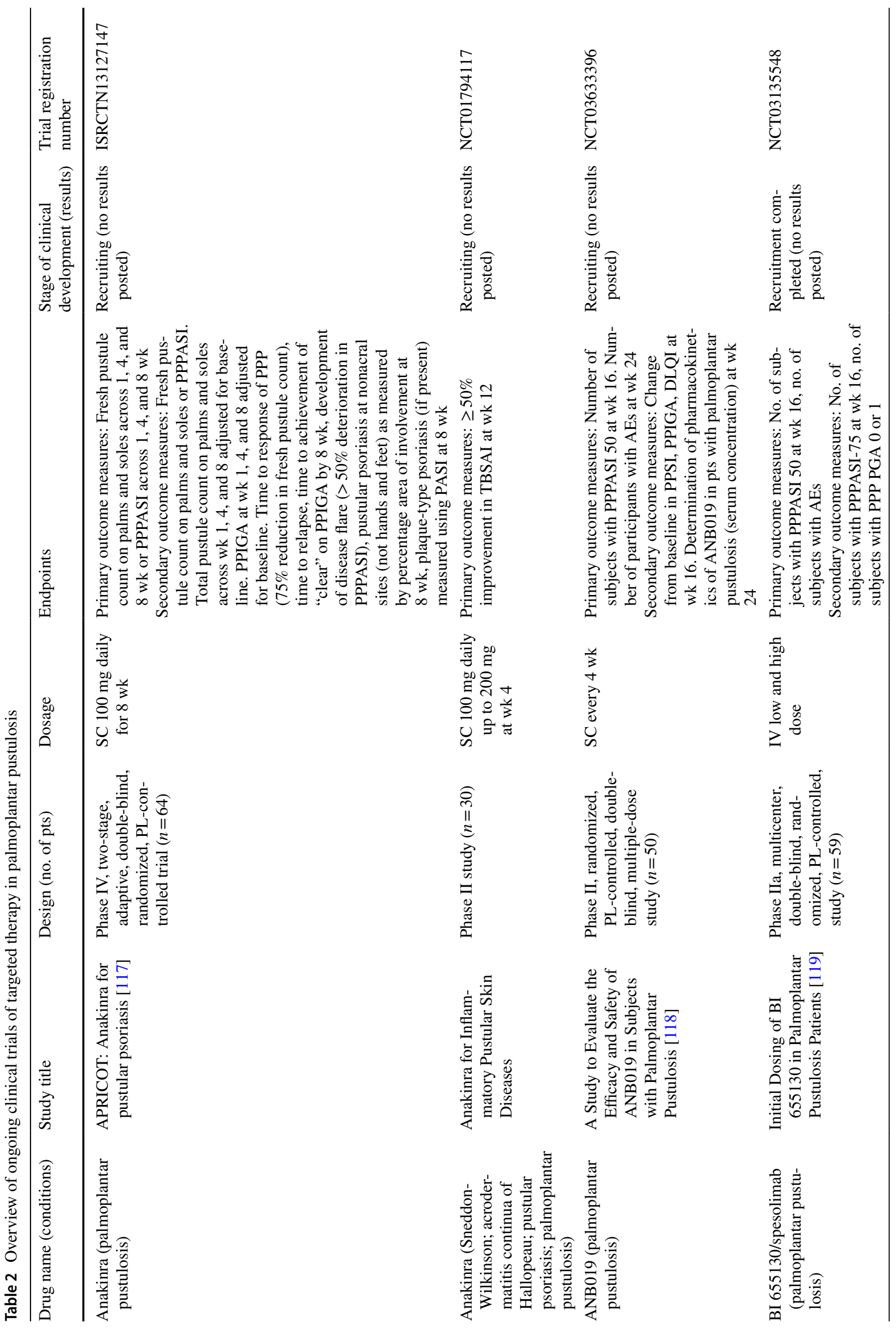




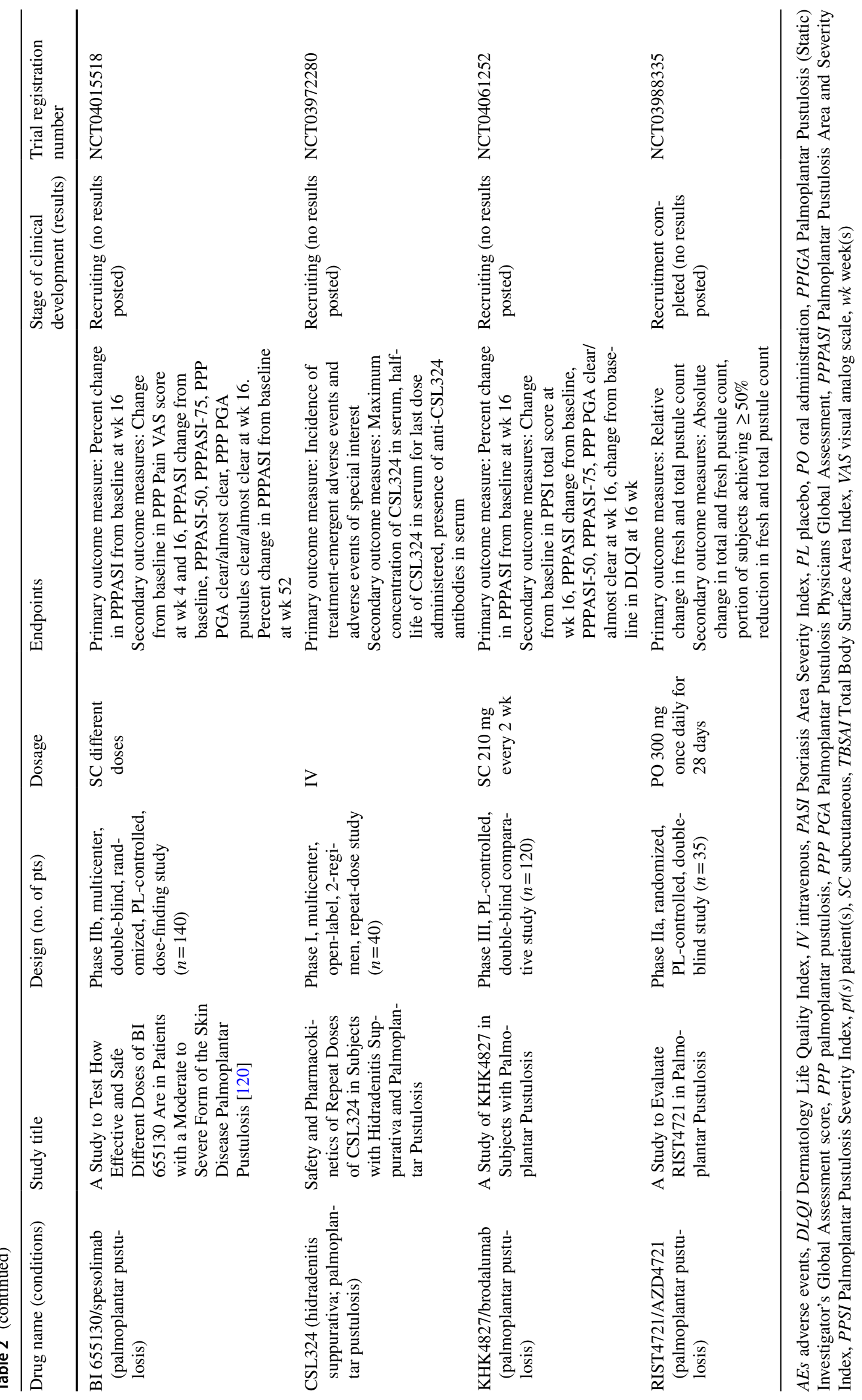


published the results of a randomized, double-blind, placebocontrolled clinical trial of guselkumab in 49 patients with PPP that showed the clinical efficacy of guselkumab at week 16; however, the onset of clinical response was observed at week 2. A phase III, multicenter, randomized, doubleblind, placebo-controlled study of the efficacy and safety of guselkumab in 159 participants with PPP was recently published [105]. It showed that guselkumab $100 \mathrm{mg}$ and $200 \mathrm{mg}$ resulted in significant improvement in PPPASI score at week 16 , but this was statistically significant only for guselkumab $100 \mathrm{mg}$ (least-squares mean change in PPPASI score from baseline was -15.3 for guselkumab $100 \mathrm{mg}$ vs. -7.6 for placebo; $p<0.001)$. Further reductions in PPPASI and PPSI scores in both the 100- and 200-mg groups were observed up to week 52. PPPASI-75 response at week 52 was reached in $55.6 \%$ of patients receiving guselkumab $100 \mathrm{mg}$ and in $59.6 \%$ those receiving guselkumab $200 \mathrm{mg}$ [105].

\subsubsection{TNF Inhibitors}

As far as TNF inhibitors are concerned, only one randomized, placebo-controlled prospective study has evaluated etanercept in PPP; it showed a decrease in median PPPASI score that was significant for subjects treated with etanercept compared with placebo at week $24(p=0.038)$, but with no differences between groups at week 12 [106]. In a retrospective study, Philipp et al. [107] presented two cases of PPP treated with combination therapy of adalimumab and methotrexate or acitretin with good clinical response.

\subsubsection{IL-17 Inhibitors}

Among the IL-17 inhibitors, secukinumab and brodalumab have been investigated for the treatment of PPP [108, 109]. In a multicenter, randomized, double-blind clinical trial (2PRECISE) involving over 200 patients with PPP, secukinumab $300 \mathrm{mg}$ and $150 \mathrm{mg}$ were compared with placebo in the treatment of PPP. At week 52, a total of $41.8 \%$ of the patients receiving secukinumab $300 \mathrm{mg}$ reached PPPASI-75, and $43.1 \%$ had a DLQI response of 0 or 1 [108].

A case series of four patients receiving brodalumab reported a lack of efficacy or moderate improvement in the treatment of PPP [109]. A phase III placebo-controlled study on the efficacy of brodalumab in subjects with PPP is ongoing (Table 2).

\subsubsection{Phosphodiesterase-4 Inhibitor}

Four papers have published promising data on apremilast in the treatment of PPP [110-113]. Two retrospective studies (with a total of 12 subjects) investigated apremilast in combination with ustekinumab, methotrexate, or ixekizumab and showed good clinical response [110, 113]. Another four cases of PPP successfully treated with apremilast in monotherapy have also been published [111, 112]. Prospective studies in more patients are needed to confirm these observations.

Clinical studies comparing the effectiveness of these targeted therapies already approved for psoriasis would be of interest, as well as other approved targeted therapies with the same mechanism of action (e.g., ixekizumab, which blocks IL-17, and risankizumab, which blocks IL-23). While their efficacy in PPP is lower than that in psoriasis vulgaris, they appear to be good therapeutic options in severe PPP resistant to classical treatment. It is worth noting that, in Japan, guselkumab is approved for the therapy of patients with PPP that is resistant to treatment.

\subsection{Emerging Agents}

\subsubsection{IL-8 Inhibitors}

Skov et al. [114] reported on the efficacy of HuMab 10F8, an anti-IL-8 monoclonal antibody, in PPP in an open-label multicenter study with a single-dose dose-escalation setup. A total of $37 \%$ of subjects at week 4 and $61 \%$ of subjects at week 8 experienced a clinical response (a decrease of $\geq 50 \%$ in number of fresh pustules). Moreover, in the high-dose group, all seven of the patients showed at least a $50 \%$ reduction in number of fresh pustules, with four patients having a reduction of $75 \%$ from baseline to week 8 [114]. The drug is not approved in any indication, and no further reports of the use of this agent in PPP have been published.

However, a randomized, double-blind, placebo-controlled, phase IIa study is currently evaluating RIST4721 (also known as AZD4721). RIST4721 is an orally administered molecule that exerts an anti-inflammatory effect by blocking CXCR2 (IL-8B receptor) on the surface of inflammatory cells.

\subsubsection{IL-36 and IL-1 Inhibitors}

Recent studies on the treatment of PPP focus on blockage of IL-36 or IL-1 pathways, which play an important role in innate immunity. Three studies are currently evaluating the use of monoclonal antibodies that block the IL-36 receptor in PPP: ANB019 and BI 655130 (spesolimab) (Table 2). Other studies are also investigating the use of BI 655130 in generalized pustular psoriasis, ulcerative colitis, Crohn disease, and atopic dermatitis. The first publication of the phase I study of BI 655130 in generalized pustular psoriasis showed that the drug was effective in all seven patients after a single intravenous dose [115]. Five patients by week 1 and all patients by week 4 achieved a Generalized Pustular Psoriasis Physician Global Assessment score of 0 or 1, with the score maintained up to week 20. Interestingly, only three 
patients had a homozygous IL36RN mutation, and one also had the CARD14 mutation, indicating that BI 655130 was effective in GPP regardless of the presence of IL36RN mutations. This is of great importance, as genetic studies have shown that IL36RN mutations were present in only in a low percentage of patients with PPP [41, 42, 44, 115].

Two further studies of anakinra in PPP are ongoing [117]. Anakinra is an IL-1 receptor antagonist that is currently registered for rheumatic arthritis, Still's disease, and cryopyrin-associated periodic syndromes. Clinical trials are being conducted in many other conditions, including inflammatory pustular diseases and hidradenitis suppurativa. Tauber et al. [116] published two cases of severe PPPP treated with subcutaneous anakinra $100 \mathrm{mg}$, with only partial clinical response. The treatment was stopped after 3 and 2 months because of lack of efficacy or side effects, respectively [116].

\subsubsection{Granulocyte Colony-Stimulating Factor Receptor Inhibitor}

CSL324 is a recombinant anti-granulocyte colony-stimulating factor (G-CSF) receptor monoclonal antibody. A phase I, multicenter, open-label study is currently underway for CSL324 in PPP and hidradenitis suppurativa.

\section{Conclusion}

PPP is a chronic, treatment-resistant, debilitating skin disease belonging to the spectrum of psoriasis. The recent publications in PPP focus on genetic differences between pustular phenotypes and the role of IL-17 and IL-36 pathways and microbiomes in the etiopathogenesis. Clinical trials are evaluating or have evaluated targeted therapies in PPP for more than 12 molecules, including CXCR2 (IL-8 receptor type B), G-CSF receptor, IL-1 receptor, IL-8, IL-12, IL-23, IL-17A, IL-17 receptor, IL-36 receptor, PDE-4, and TNF $\alpha$.

\section{Compliance with Ethical Standards}

Conflict of interest M. Misiak-Galazka, J. Zozula, and L. Rudnicka have no conflicts of interest that are directly relevant to the content of this article.

Funding No sources of funding were used to conduct this study or prepare this manuscript.

Open Access This article is licensed under a Creative Commons Attribution-NonCommercial 4.0 International License, which permits any non-commercial use, sharing, adaptation, distribution and reproduction in any medium or format, as long as you give appropriate credit to the original author(s) and the source, provide a link to the Creative Commons licence, and indicate if changes were made. The images or other third party material in this article are included in the article's Creative
Commons licence, unless indicated otherwise in a credit line to the material. If material is not included in the article's Creative Commons licence and your intended use is not permitted by statutory regulation or exceeds the permitted use, you will need to obtain permission directly from the copyright holder.To view a copy of this licence, visit http://creativecommons.org/licenses/by-nc/4.0/.

\section{References}

1. Mrowietz U, Van De Kerkhof PCM. Management of palmoplantar pustulosis: do we need to change? Br J Dermatol. 2011;164(5):942-6.

2. Kubota K, Kamijima Y, Sato T, Ooba N, Koide D, Iizuka H, et al. Epidemiology of psoriasis and palmoplantar pustulosis: a nationwide study using the Japanese national claims database. BMJ Open. 2015;5(1):e006450.

3. Michaëlsson G, Kristjánsson G, Pihl Lundin I, Hagforsen E. Palmoplantar pustulosis and gluten sensitivity: a study of serum antibodies against gliadin and tissue transglutaminase, the duodenal mucosa and effects of gluten-free diet. Br J Dermatol. 2007;156(4):659-66.

4. Adisen E, Tekin O, Gulekon A, Gurer MA. A retrospective analysis of treatment responses of palmoplantar psoriasis in 114 patients. J Eur Acad Dermatol Venereol. 2009;23(7):814-9.

5. Brunasso AMG, Puntoni M, Aberer W, Delfino C, Fancelli L, Massone C. Clinical and epidemiological comparison of patients affected by palmoplantar plaque psoriasis and palmoplantar pustulosis: a case series study. Br J Dermatol. 2013;168(6):1243-51.

6. Eriksson MO, Hagforsen E, Lundin IP, Michaëlsson G. Palmoplantar pustulosis: a clinical and immunohistological study. Br J Dermatol. 1998;138(3):390-8.

7. Misiak-Galazka M, Wolska H, Galazka A, Kwiek B, Rudnicka L. General characteristics and comorbidities in patients with palmoplantar pustulosis. Acta Dermatovenerol Croat. 2018;26(2):109-18.

8. Miot H, Miot L, Lopes P, Haddad G, Marques S. Association between palmoplantar pustulosis and cigarette smoking in Brazil: a case-control study. J Eur Acad Dermatol Venereol. 2009;23(10):1173-7.

9. Wilsmann-Theis D, Jacobi A, Frambach Y, Philipp S, Weyergraf A, Schill T, et al. Palmoplantar pustulosis-a cross-sectional analysis in Germany. Dermatol Online J. 2017;23:4.

10. Burden AD, Kemmett $\mathrm{D}$. The spectrum of nail involvement in palmoplantar pustulosis. Br J Dermatol. 1996;134(6):1079-82.

11. Hiraiwa T, Yamamoto T. Nail involvement associated with palmoplantar pustulosis. Int J Dermatol. 2017;56(2):e28-9.

12. Gimenéz-García R, Sánchez-Ramón S, Cuellar-Olmedo LA. Palmoplantar pustulosis: a clinicoepidemiological study. The relationship between tobacco use and thyroid function. J Eur Acad Dermatol Venereol. 2003;17(3):276-9.

13. Takahara M, Hirata Y, Nagato T, Kishibe K, Katada A, Hayashi $\mathrm{T}$, et al. Treatment outcome and prognostic factors of tonsillectomy for palmoplantar pustulosis and pustulotic arthro-osteitis: a retrospective subjective and objective quantitative analysis of 138 patients. J Dermatol. 2018;45(7):812-23.

14. Nozawa H, Kishibe K, Takahara M, Harabuchi Y. Expression of cutaneous lymphocyte-associated antigen (CLA) in tonsillar $\mathrm{T}$-cells and its induction by in vitro stimulation with alpha-streptococci in patients with pustulosis palmaris et plantaris (PPP). Clin Immunol. 2005;116(1):42-53.

15. Kouno M, Nishiyama A, Minabe M, Iguchi N, Ukichi K, Nomura $\mathrm{T}$, et al. Retrospective analysis of the clinical response of 
palmoplantar pustulosis after dental infection control and dental metal removal. J Dermatol. 2017;44(6):695-8.

16. Masui Y, Ito A, Akiba Y, Uoshima K, Abe R. Dental metal allergy is not the main cause of palmoplantar pustulosis. J Eur Acad Dermatol Venereol. 2019;33(4):e180-1.

17. Ito T, Mori T, Fujiyama T, Tokura Y. Dramatic exacerbation of palmoplantar pustulosis following strongly positive nickel patch testing. Int J Dermatol. 2014;53(5):e327-9.

18. Yanagi T, Shimizu T, Abe R, Shimizu H. Zinc dental fillings and palmoplantar pustulosis. Lancet. 2005;366(9490):1050.

19. Watanabe K, Sugai T, Shoji A, Asoh S, Hashimoto Y, Inoue A. Metal allergy in patients with palmoplantar pustulosis. Skin Res. 1989;31(SUPPL. 7):251-6.

20. Hosoki M, Bando E, Asaoka K, Takeuchi H, Nishigawa K. Assessment of allergic hypersensitivity to dental materials. Biomed Mater Eng. 2009;19(1):53-61.

21. Brunasso Vernetti AMG, Puntoni M, Massone C. Palmoplantar pustulosis and allergies: a systematic review. Dermatol Pract Concept. 2019;9(2):105-10.

22. Bae JM, Lee HH, Lee BI, Lee KM, Eun SH, Cho ML, et al. Incidence of psoriasiform diseases secondary to tumour necrosis factor antagonists in patients with inflammatory bowel disease: a nationwide population-based cohort study. Aliment Pharmacol Ther. 2018;48(2):196-205.

23. Brunasso AMG, Massone C. Can we really separate palmoplantar pustulosis from psoriasis? J Eur Acad Dermatol Venereol. 2010;24(5):619-21.

24. Ataş H, Gönül M. Insulin resistance, diabetes mellitus and thyroid dysfunction in patients with palmoplantar pustulosis: a casecontrolled study. Post Dermatol Alergol. 2017;34(3):268-72.

25. Trattner H, Blüml S, Steiner I, Plut U, Radakovic S, Tanew A. Quality of life and comorbidities in palmoplantar pustulosisa cross-sectional study on 102 patients. J Eur Acad Dermatol Venereol. 2017;31(10):1681-5.

26. Becher G, Jamieson L, Leman J. Palmoplantar pustulosis-a retrospective review of comorbid conditions. J Eur Acad Dermatol Venereol. 2015;29(9):1854-6.

27. Benhamou C, Chamot AM, Kahn MF. SAPHO syndrome. Ann Dermatol Venereol. 1988;115(5):613-8.

28. Hagforsen E, Michaelsson K, Lundgren E, Olofsson H, Petersson A, Lagumdzija A, et al. Women with palmoplantar pustulosis have disturbed calcium homeostasis and a high prevalence of diabetes mellitus and psychiatric disorders: a case-control study. Acta Derm Venereol. 2005;85(3):225-32.

29. Lesiak A, Bednarski I, Pałczyńska M, Kumiszcza E, KraskaGacka M, Woźniacka A, et al. Are interleukin-15 and -22 a new pathogenic factor in pustular palmoplantar psoriasis? Post Dermatol Alergol. 2016;33(5):336-9.

30. Weisenseel P, Kuznetsov AV, Ruzicka T, Prinz JC. Palmoplantar pustulosis is not inevitably associated with antigliadin antibodies. Br J Dermatol. 2007;156(6):1399-400.

31. Chung J, Duffin KC, Takeshita J, Shin DB, Krueger GG, Robertson $\mathrm{AD}$, et al. Palmoplantar psoriasis is associated with greater impairment of health-related quality of life compared with moderate to severe plaque psoriasis. J Am Acad Dermatol. 2014;71(4):623-32.

32. Pettey AA, Balkrishnan R, Rapp SR, Fleischer AB, Feldman SR. Patients with palmoplantar psoriasis have more physical disability and discomfort than patients with other forms of psoriasis: implications for clinical practice. J Am Acad Dermatol. 2003;49(2):271-5.

33. Sampogna F, Tabolli S, Söderfeldt B, Axtelius B, Aparo U, Abeni D. Measuring quality of life of patients with different clinical types of psoriasis using the SF-36. Br J Dermatol. 2006;154(5):844-9.
34. Farley E, Masrour S, McKey J, Menter A. Palmoplantar psoriasis: a phenotypical and clinical review with introduction of a new quality-of-life assessment tool. J Am Acad Dermatol. 2009;60(6):1024-31.

35. Ding L, Wang X, Hong X, Lu L, Liu D. IL-36 cytokines in autoimmunity and inflammatory disease. Oncotarget. 2018;9(2):2895-901.

36. Setta-Kaffetzi N, Simpson MA, Navarini AA, Patel VM, Lu HC, Allen MH, et al. AP1S3 mutations are associated with pustular psoriasis and impaired Toll-like receptor 3 trafficking. Am J Hum Genet. 2014;94(5):790-7.

37. Zotti T, Polvere I, Voccola S, Vito P, Stilo R. CARD14/CARMA2 signaling and its role in inflammatory skin disorders. Front Immunol. 2018;9:2167.

38. Marrakchi S, Guigue P, Renshaw BR, Puel A, Pei XY, Fraitag S, et al. Interleukin-36-receptor antagonist deficiency and generalized pustular psoriasis. N Engl J Med. 2011;365(7):620-8.

39. Onoufriadis A, Simpson MA, Pink AE, Di Meglio P, Smith $\mathrm{CH}$, Pullabhatla V, et al. Mutations in IL36RN/IL1F5 are associated with the severe episodic inflammatory skin disease known as generalized pustular psoriasis. Am J Hum Genet. 2011;89(3):432-7.

40. Abbas O, Itani S, Ghosn S, Kibbi AG, Fidawi G, Farooq M, et al. Acrodermatitis continua of Hallopeau is a clinical phenotype of DITRA: evidence that it is a variant of pustular psoriasis. Dermatology. 2013;226(1):28-31.

41. Mossner R, Wilsmann-Theis D, Oji V, Gkogkolou P, Lohr S, Schulz $\mathrm{P}$, et al. The genetic basis for most patients with pustular skin disease remains elusive. Br J Dermatol. 2018;178(3):740-8.

42. Takahashi T, Fujimoto N, Kabuto M, Nakanishi T, Tanaka T. Mutation analysis of IL36RN gene in Japanese patients with palmoplantar pustulosis. J Dermatol. 2017;44(1):80-3.

43. Wang TS, Chiu HY, Hong JB, Chan CC, Lin SJ, Tsai TF. Correlation of IL36RN mutation with different clinical features of pustular psoriasis in Chinese patients. Arch Dermatol Res. 2016;308(1):55-63.

44. Twelves S, Mostafa A, Dand N, Burri E, Farkas K, Wilson R, et al. Clinical and genetic differences between pustular psoriasis subtypes. J Allergy Clin Immunol. 2019;143(3):1021-6.

45. Mossner R, Frambach Y, Wilsmann-Theis D, Lohr S, Jacobi A, Weyergraf A, et al. Palmoplantar pustular psoriasis is associated with missense variants in CARD14, but not with loss-of-function mutations in IL36RN in European patients. J Investig Dermatol. 2015;135(10):2538-41.

46. Tobita R, Egusa C, Maeda T, Abe N, Sakai N, Suzuki S, et al. A novel CARD14 variant, homozygous c.526G > C (p.Asp176His), in an adolescent Japanese patient with palmoplantar pustulosis. Clin Exp Dermatol. 2019;44(6):694-6.

47. Asumalahti K, Ameen M, Suomela S, Hagforsen E, Michaëlsson G, Evans J, et al. Genetic analysis of PSORS1 distinguishes guttate psoriasis and palmoplantar pustulosis. J Investig Dermatol. 2003;120(4):627-32.

48. Mössner R, Kingo K, Kleensang A, Krüger U, König IR, Silm $\mathrm{H}$, et al. Association of TNF-238 and -308 promoter polymorphisms with psoriasis vulgaris and psoriatic arthritis but not with pustulosis palmoplantaris [6]. J Investig Dermatol. 2005;124(1):282-4.

49. Han JW, Wang Y, Alateng C, Li HB, Bai YH, Lyu XX, et al. Tumor necrosis factor-alpha induced protein 3 interacting protein 1 gene polymorphisms and pustular psoriasis in Chinese Han population. Chin Med J (Engl). 2016;129(13):1519-24.

50. Masuda-Kuroki K, Murakami M, Kishibe M, Kobayashi S, Okubo Y, Yamamoto T, et al. Diagnostic histopathological features distinguishing palmoplantar pustulosis from pompholyx. J Dermatol. 2019;46(5):399-408. 
51. Yoon SY, Park HS, Yoon HS, Chung JH, Cho S. Utility of epithelial membrane antigen immunostaining in the differentiation between palmoplantar pustulosis and pompholyx. J Eur Acad Dermatol Venereol. 2013;27(8):1054-6.

52. Yoon SY, Park HS, Lee JH, Cho S. Histological differentiation between palmoplantar pustulosis and pompholyx. J Eur Acad Dermatol Venereol. 2013;27(7):889-93.

53. Kim DY, Kim JY, Kim TG, Kwon JE, Sohn H, Park J, et al. A comparison of inflammatory mediator expression between palmoplantar pustulosis and pompholyx. J Eur Acad Dermatol Venereol. 2013;27(12):1559-65.

54. Murakami M, Ohtake T, Horibe Y, Ishida-Yamamoto A, Morhenn VB, Gallo RL, et al. Acrosyringium is the main site of the vesicle/pustule formation in palmoplantar pustulosis. J Investig Dermatol. 2010;130(8):2010-6.

55. Hagforsen E, Edvinsson M, Nordlind K, Michaëlsson G. Expression of nicotinic receptors in the skin of patients with palmoplantar pustulosis. Br J Dermatol. 2002;146(3):383-91.

56. Hagforsen E, Einarsson A, Aronsson F, Nordlind K, Michaelsson G. The distribution of choline acetyltransferase- and acetylcholinesterase-like immunoreactivity in the palmar skin of patients with palmoplantar pustulosis. Br J Dermatol. 2000;142(2):234-42.

57. Hagforsen E, Hedstrand H, Nyberg F, Michaelsson G. Novel findings of Langerhans cells and interleukin-17 expression in relation to the acrosyringium and pustule in palmoplantar pustulosis. $\mathrm{Br}$ J Dermatol. 2010;163(3):572-9.

58. Ueda S, Takahara M, Tohtani T, Yoshizaki T, Kishibe K, Harabuchi Y. Up-regulation of $\beta 1$ integrin on tonsillar T cells and its induction by in vitro stimulation with $\alpha$-streptococci in patients with pustulosis palmaris et plantaris. J Clin Immunol. 2010;30(6):861-71.

59. Yoshizaki T, Bandoh N, Ueda S, Nozawa H, Goto T, Kishibe K, et al. Up-regulation of CC chemokine receptor 6 on tonsillar T cells and its induction by in vitro stimulation with $\alpha$-streptococci in patients with pustulosis palmaris et plantaris. Clin Exp Dermatol. 2009;157(1):71-82.

60. Takahara M, Kishibe K, Nozawa H, Harabuchi Y. Increase of activated T-cells and up-regulation of Smad7 without elevation of TGF-beta expression in tonsils from patients with pustulosis palmaris et plantaris. Clin Immunol. 2005;115(2):192-9.

61. Bissonnette R, Fuentes-Duculan J, Mashiko S, Li X, Bonifacio $\mathrm{KM}$, Cueto I, et al. Palmoplantar pustular psoriasis (PPPP) is characterized by activation of the IL-17A pathway. J Dermatol Sci. 2017;85(1):20-6.

62. Bissonnette R, Nigen S, Langley RG, Lynde CW, Tan J, FuentesDuculan J, et al. Increased expression of IL-17A and limited involvement of IL-23 in patients with palmo-plantar (PP) pustular psoriasis or PP pustulosis; results from a randomised controlled trial. J Eur Acad Dermatol Venereol. 2014;28(10):1298-305.

63. Lin AM, Rubin CJ, Khandpur R, Wang JY, Riblett M, Yalavarthi S, et al. Mast cells and neutrophils release IL-17 through extracellular trap formation in psoriasis. J Immunol. 2011;187(1):490-500.

64. Ozawa M, Terui T, Tagami H. Localization of IL-8 and complement components in lesional skin of psoriasis vulgaris and pustulosis palmaris et plantaris. Dermatology. 2005;211(3):249-55.

65. Murakami M, Hagforsen E, Morhenn V, Ishida-Yamamoto A, Iizuka $\mathrm{H}$. Patients with palmoplantar pustulosis have increased IL-17 and IL-22 levels both in the lesion and serum. Exp Dermatol. 2011;20(10):845-7.

66. Murakami M, Kaneko T, Nakatsuji T, Kameda K, Okazaki H, Dai X, et al. Vesicular LL-37 contributes to inflammation of the lesional skin of palmoplantar pustulosis. PLoS One. 2014;9(10):e110677.
67. Xiaoling Y, Chao W, Wenming W, Feng L, Hongzhong J. Interleukin (IL)-8 and IL-36 $\gamma$ but not IL-36Ra are related to acrosyringia in pustule formation associated with palmoplantar pustulosis. Clin Exp Dermatol. 2019;44(1):52-7.

68. Jiang WG, Sanders AJ, Ruge F, Harding KG. Influence of interleukin-8 (IL-8) and IL-8 receptors on the migration of human keratinocytes, the role of PLC-gamma and potential clinical implications. Exp Ther Med. 2012;3(2):231-6.

69. Wolk K, Frambach Y, Jacobi A, Wilsmann-Theis D, Phillipp S, Witte-Händel E, et al. Increased levels of lipocalin 2 in palmoplantar pustular psoriasis. J Dermatol Sci. 2018;90(1):68-74.

70. Masuda-Kuroki K, Murakami M, Tokunaga N, Kishibe M, Mori $\mathrm{H}$, Utsunomiya R, et al. The microbiome of the "sterile" pustules in palmoplantar pustulosis. Exp Dermatol. 2018;27(12):1372-7.

71. Kouno M, Akiyama Y, Minabe M, Iguchi N, Nomura T, Ishihara $\mathrm{K}$, et al. Dysbiosis of oral microbiota in palmoplantar pustulosis patients. J Dermatol Sci. 2019;93(1):67-9.

72. Muro M, Kawakami H, Matsumoto Y, Abe N, Tsuboi R, Okubo Y. Topical combination therapy with vitamin $\mathrm{D}_{3}$ and corticosteroid ointment for palmoplantar pustulosis: a prospective, randomized, left-right comparison study. J Dermatol Treat. 2016;27(1):51-3.

73. Umezawa Y, Nakagawa H, Tamaki K. Phase III clinical study of maxacalcitol ointment in patients with palmoplantar pustulosis: a randomized, double-blind, placebo-controlled trial. J Dermatol. 2016;43(3):288-93.

74. Robbins AB, Gor A, Bui MR. Topical crisaborole-a potential treatment for recalcitrant palmoplantar psoriasis. JAMA Dermatol. 2018;154(9):1096-7.

75. Laino L, DiCarlo A. Palmoplantar pustular psoriasis: clinical and video thermographic evaluation before and after topical tacrolimus treatment. Arch Dermatol. 2011;147(6):760.

76. Engin B, Oguz O. Evaluation of time-dependent response to psoralen plus UVA (PUVA) treatment with topical 8-methoxypsoralen (8-MOP) gel in palmoplantar dermatoses. Int J Dermatol. 2005;44(4):337-9.

77. Riad K, Felix P, Dorit S, Gregory K, Nadim K, Henri T. The use of topical PUVA for palmoplantar dermatoses. J Dermatol Treat. 2006;17(5):304-7.

78. Jensen L, Stensgaard A, Andersen KE. Psoralen plus ultraviolet A (PUVA) soaks and UVB TL01 treatment for chronic hand dermatoses. Dermatol Rep. 2012;4(1).

79. Ettler K, Richards B. Acitretin therapy for palmoplantar pustulosis combined with UVA and topical 8-MOP. Int J Dermatol. 2001;40(8):541-2.

80. Carrascosa JM, Plana A, Ferrándiz C. Effectiveness and safety of psoralen-UVA (PUVA) topical therapy in palmoplantar psoriasis: a report on 48 patients. Actas Dermo-Sifiliograficas. 2013;104(5):418-25.

81. Kawada A, Matsuda H, Oiso N. Efficacy and safety of targeted narrowband ultraviolet B therapy using a flat-type fluorescent lamp for the treatment of palmoplantar pustulosis. J Dermatol. 2013;40(9):754-5.

82. Su LN, Ren J, Cheng SM, Liu JL, Ding YF, Zhu NW. UVA1 vs. narrowband UVB phototherapy in the treatment of palmoplantar pustulosis: a pilot randomized controlled study. Lasers Med Sci. 2017;32(8):1819-23.

83. Lozinski A, Barzilai A, Pavlotsky F. Broad-band UVB versus paint PUVA for palmoplantar psoriasis treatment. J Dermatol Treat. 2016;27(3):221-3.

84. Su LN, Xu X, Tang L, Yu N, Ding YF. UVA1 phototherapy in the treatment of palmoplantar pustulosis: a pilot prospective study. Lasers Med Sci. 2016;31(8):1641-3.

85. Nisticò SP, Saraceno R, Schipani C, Costanzo A, Chimenti S. Different applications of monochromatic excimer light in skin diseases. Photomed Laser Surg. 2009;27(4):647-54. 
86. Aubin F, Vigan M, Puzenat E, Blanc D, Drobacheff C, Deprez P, et al. Evaluation of a novel 308-nm monochromatic excimer light delivery system in dermatology: a pilot study in different chronic localized dermatoses. Br J Dermatol. 2005;152(1):99-103.

87. Fumimori T, Tsuruta D, Kawakami T, Ohata C, Furumura M, Hashimoto T. Effect of monochromatic excimer light on palmoplantar pustulosis: a clinical study performed in a private clinic by a dermatological specialist. J Dermatol. 2013;40(12):1004-7.

88. Furuhashi T, Torii K, Kato H, Nishida E, Saito C, Morita A. Efficacy of excimer light therapy $(308 \mathrm{~nm})$ for palmoplantar pustulosis with the induction of circulating regulatory T cells. Exp Dermatol. 2011;20(9):768-70.

89. Han L, Somani AK, Huang Q, Fang X, Jin Y, Xiang LH, et al. Evaluation of 308-nm monochromatic excimer light in the treatment of psoriasis vulgaris and palmoplantar psoriasis. Photodermatol Photoimmunol Photomed. 2008;24(5):231-6.

90. Kim JY, Kang HY, Lee ES, Kim YC. Topical 5-aminolaevulinic acid photodynamic therapy for intractable palmoplantar psoriasis. J Dermatol. 2007;34(1):37-40.

91. Wong TH, Morton CA, Collier N, Haylett A, Ibbotson S, McKenna KE, et al. British Association of Dermatologists and British Photodermatology Group guidelines for topical photodynamic therapy 2018. Br J Dermatol. 2019;180(4):730-9.

92. Fenton L, Dawe RS. Six years' experience of grenz ray therapy for the treatment of inflammatory skin conditions. Clin Exp Dermatol. 2016;41(8):864-70.

93. Sevrain M, Richard MA, Barnetche T, Rouzaud M, Villani AP, Paul C, et al. Treatment for palmoplantar pustular psoriasis: systematic literature review, evidence-based recommendations and expert opinion. J Eur Acad Dermatol Venereol. 2014;28(Suppl 5):13-6.

94. Irla N, Navarini AA, Yawalkar N. Alitretinoin abrogates innate inflammation in palmoplantar pustular psoriasis. Br J Dermatol. 2012;167(5):1170-4.

95. Reich K, Graff O, Mehta N. Oral alitretinoin treatment in patients with palmoplantar pustulosis inadequately responding to standard topical treatment: a randomised phase II study. Br J Dermatol. 2016;174(6):1277-81.

96. Brunasso AMG, Massone C. Alitretinoin therapy for palmoplantar pustulosis. Br J Dermatol. 2017;177(2):578-9.

97. Obeid G, Do G, Katsahian S, Kirby L, Hughes C, Le Cleach L. Interventions for chronic palmoplantar pustulosis. Cochrane Database Syst Rev. 2015;2015(4).

98. Au SC, Goldminz AM, Kim N, Dumont N, Michelon M, Volf $\mathrm{E}$, et al. Investigator-initiated, open-label trial of ustekinumab for the treatment of moderate-to-severe palmoplantar psoriasis. J Dermatol Treat. 2013;24(3):179-87.

99. Morales-Múnera C, Vilarrasa E, Puig L. Efficacy of ustekinumab in refractory palmoplantar pustular psoriasis. Br J Dermatol. 2013;168(4):820-4.

100. Hegazy S, Konstantinou MP, Bulai Livideanu C, Tauber M, Uthurriague C, Paul C. Efficacy of ustekinumab in palmoplantar pustulosis. J Eur Acad Dermatol Venereol. 2018;32(5):e204-6.

101. Buder V, Herberger K, Jacobi A, Augustin M, Radtke MA. Ustekinumab in the treatment of palmoplantar pustular psoriasis - a case series of nine patients. J Dtsch Dermatol Ges. 2016;14(11):1108-13.

102. Bertelsen T, Kragballe K, Johansen C, Iversen L. Efficacy of ustekinumab in palmoplantar pustulosis and palmoplantar pustular psoriasis. Int J Dermatol. 2014;53(10):e464-6.

103. Gerdes S, Franke J, Domm S, Mrowietz U. Ustekinumab in the treatment of palmoplantar pustulosis. Br J Dermatol. 2010;163(5):1116-8.

104. Terui T, Kobayashi S, Okubo Y, Murakami M, Hirose K, Kubo $\mathrm{H}$. Efficacy and safety of guselkumab, an anti-interleukin 23 monoclonal antibody, for palmoplantar pustulosis: a randomized clinical trial. JAMA Dermatol. 2018;154(3):309-16.

105. Terui T, Kobayashi S, Okubo Y, Murakami M, Zheng R, Morishima H, et al. Efficacy and safety of guselkumab in Japanese patients with palmoplantar pustulosis: a phase 3 randomized clinical trial. JAMA Dermatol. 2019. https://doi.org/10.1001/ jamadermatol.2019.1394.

106. Bissonnette R, Poulin Y, Bolduc C, Maari C, Provost N, Syrotuik $\mathrm{J}$, et al. Etanercept in the treatment of palmoplantar pustulosis. J Drugs Dermatol. 2008;7(10):940-6.

107. Philipp S, Wilsmann-Theis D, Weyergraf A, Rotterdam S, Frambach Y, Gerdes S, et al. Combination of adalimumab with traditional systemic antipsoriatic drugs - a report of 39 cases. J Dtsch Dermatol Ges. 2012;10(11):821-38.

108. Mrowietz U, Bachelez H, Burden AD, Rissler M, Sieder C, Orsenigo R, et al. Secukinumab for moderate-to-severe palmoplantar pustular psoriasis: results of the 2PRECISE study. J Am Acad Dermatol. 2019;80(5):1344-52.

109. Pinter A, Wilsmann-Theis D, Peitsch WK, Mössner R. Interleukin-17 receptor A blockade with brodalumab in palmoplantar pustular psoriasis: report on four cases. J Dermatol. 2019;46(4):426-30.

110. Alomran A, Zancanaro P, Prussick L, Abudu M, Her MJ, Kachuk $\mathrm{C}$, et al. Apremilast in combination with an interleukin 17A inhibitor in the treatment of recalcitrant palmoplantar psoriasis: a chart review. J Psoriasis Psoriatic Arthritis. 2018;3(4):122-5.

111. Eto A, Nakao M, Furue M. Three cases of palmoplantar pustulosis successfully treated with apremilast. J Dermatol. 2019;46(1):e29-30.

112. Haebich G, Kalavala M. Successful treatment of refractory palmoplantar pustulosis with apremilast. Clin Exp Dermatol. 2017;42(4):471-3.

113. Mikhailitchenko AL, Crowley EL, Gooderham MJ. Eight-patient case series of palmoplantar pustulosis treated successfully with apremilast. J Psoriasis Psoriatic Arthritis. 2019;4(1):7-10.

114. Skov L, Beurskens FJ, Zachariae COC, Reitamo S, Teeling J, Satijn D, et al. IL-8 as antibody therapeutic target in inflammatory diseases: reduction of clinical activity in palmoplantar pustulosis. J Immunol. 2008;181(1):669-79.

115. Bachelez H, Choon SE, Marrakchi S, Burden AD, Tsai TF, Morita A, et al. Inhibition of the interleukin-36 pathway for the treatment of generalized pustular psoriasis. N Engl J Med. 2019;380(10):981-3.

116. Tauber M, Viguier M, Alimova E, Petit A, Lioté F, Smahi A, et al. Partial clinical response to anakinra in severe palmoplantar pustular psoriasis. Br J Dermatol. 2014;171(3):646-9.

117. Cornelius V, Wilson R, Cro S, Barker J, Burden D, Griffiths CEM, et al. A small population, randomised, placebo-controlled trial to determine the efficacy of anakinra in the treatment of pustular psoriasis: study protocol for the APRICOT trial. Trials. 2018;19(1):534.

118. Nct. A Study to Evaluate the Efficacy and Safety of ANB019 in Subjects With Palmoplantar Pustulosis. 2018. https://clinicaltr ials.gov/show/nct03633396.

119. Nct. Initial Dosing of BI 655130 in Palmoplantar Pustulosis Patients. 2017. https://clinicaltrials.gov/show/nct03135548.

120. Nct. A Study to Test How Effective and Safe Different Doses of BI 655130 Are in Patients With a Moderate to Severe Form of the Skin Disease Palmoplantar Pustulosis. 2019. https://clinicaltr ials.gov/ct2/show/NCT04015518. 